\title{
The Effect of Tegaserod on Symptoms and Quality of Life in Korean Women with Irritable Bowel Syndrome with Constipation
}

\author{
Yong Sung Kim, M.D. ${ }^{1}$, Suck Chei Choi, M.D. ${ }^{1 *}$, Jae Myung Park, M.D. ${ }^{2}$, Chang Hwan Choi, M.D. ${ }^{3}$, Dong Ho Lee, M.D. ${ }^{4}$, \\ Hee Jung Son, M.D. ${ }^{5}$, In Kyung Sung, M.D. ${ }^{6}$, Jeong Jo Jeong, M.D. ${ }^{2}$, Joon Seong Lee, M.D. ${ }^{7}$, Ki Nam Shim, M.D. ${ }^{8}$, Kwang \\ Jae Lee, M.D. ${ }^{9}$, Su Jin Hong, M.D. ${ }^{7}$, Myung-Gyu Choi, M.D. ${ }^{2}$, and IBS Club of the Korean Society of Neurogastroenterology \\ and Motility \\ ${ }^{1}$ Wonkwang University College of Medicine, Iksan, Jeollabuk-do, Korea, ${ }^{2}$ Catholic University College of Medicine, Seoul, Korea, ${ }^{3}$ Chung-Ang \\ University College of Medicine, Seoul, Korea, ${ }^{4}$ Seoul National University Bundang Hospital, Seongnam, Gyeonggi-do, Korea, ${ }^{5}$ Sungkyunkwan \\ University College of Medicine, Seoul, Korea, ${ }^{6}$ Konkuk University College of Medicine, Seoul, Korea, ' Soonchunhyang University College of \\ Medicine, Seoul, Korea, ${ }^{8}$ Ewha Womans University College of Medicine, Seoul, Korea, ${ }^{9}$ Ajou University College of Medicine, Suwon, \\ Gyeonggi-do, Korea
}

\section{Introduction}

Tegaserod has been used for treatment of irritable bowel syndrome (IBS) but there is no data regarding its effect on Korean patients. The aim of this study was to evaluate the effect of tegaserod on symptoms and quality of life (QOL) in Korean female IBS patients with constipation and to evaluate the usefulness of the IBS-QOL in clinical study.

\section{Methods}

A prospective, open labeled, multicenter study was performed. Female patients fulfilling Rome II criteria for IBS received 6 mg of tegaserod twice a day for 4 weeks. The efficacy on IBS symptoms and QOL was assessed using 7-point scaled symptom questionnaire and IBS-QOL questionnaire, respectively.

\section{Results}

A total of 81 female patients (range 18-73 years of age) were enrolled in this study. Tegaserod therapy significantly reduced the overall symptom scores after 4 weeks $(p<0.01)$. The improved symptoms included abdominal discomfort or pain, hard or lumpy stool, straining during a bowel movement, feeling of incomplete bowel movement, and abdominal fullness or bloating. The IBS-QOL of responders to tegaserod treatment was also significantly improved after 4 weeks $(p<0.01)$. Furthermore, improvement of symptom scores significantly correlated with improvement of the IBS-QOL scores $(r=-0.60, p<0.001)$.

\section{Conclusions}

Tegaserod $6 \mathrm{mg}$ given twice daily improved the QOL as well as the bowel symptoms in Korean female IBS patients with constipation. The IBS-QOL can be used as a reliable end-point in clinical study.

(J Neurogastroenterol Motil 2010;16:61-70)

\section{Key Words}

Tegaserod, Irritable bowel syndrome, Quality of life

Received: June 19th, 2009 Accepted: November 27th, 2009

(c) This is an Open Access article distributed under the terms of the Creative Commons Attribution Non-Commercial License (http://creativecommons. org/licenses/by-nc/3.0) which permits unrestricted non-commercial use, distribution, and reproduction in any medium, provided the original work is properly cited.

*Correspondence: Suck Chei Choi, M.D.

Department of Gastroenterology, Wonkwang University Hospital, 344-2 Shinyong-dong, Iksan, Jeollabuk-do 570-711, Korea Tel: +82-63-859-2563, Fax: +82-63-855-2025, E-mail: medcsc@wmc.wonkwang.ac.kr

Financial support: This work was funded by grants from The Korean Society of Neurogastroenterology and Motility by Novartis Pharmaceuticals Corporation, Korea.

Conflicts of interest: None. 


\section{Introduction}

Irritable bowel syndrome (IBS) is a functional bowel disorder that is characterized by abdominal pain and the change of bowel habits in the absence of structural or biochemical abnormalities. ${ }^{1}$ IBS is one of the most common gastrointestinal diseases encountered by gastroenterologists in clinical practice and affects up to $25 \%$ of the population in Western countries. ${ }^{2-5}$ Now IBS is increasing in Korea and a recent study reports the prevalence of $6.6 \%$ in the Korean population. ${ }^{6}$ It is important to find a reliable end-point in clinical studies aiming to evaluate the efficacy of certain treatment modality in patient with IBS. The assessment of IBS symptoms is usually used as primary end-point in many clinical trials. However, patients with IBS suffer from not only the bowel related symptoms, but also from the poor quality of life (QOL) related to IBS. IBS has a negative impact on health related QOL and the therapeutic response of IBS-related symptoms has a corresponding improvement in health related QOL. ${ }^{7-9}$

Among the limited therapeutic options, drugs acting on serotonin (5-hydroxytrypatmine, 5-HT) receptor have been widely used because serotonin plays a critical role in the gastrointestinal tract and has been shown to influence secretory, motor and sensory function in functional gastrointestinal disorders. ${ }^{10}$ Tegaserod (Zelmac ${ }^{\circledR}$; Novartis Pharma AG, Basel, Switzerland) is an indole carboxaldehyde derivative that acts as a selective partial agonist at the $5-\mathrm{HT}_{4}$ receptor ${ }^{11}$ and has been approved for the treatment of women with IBS with constipation (C-IBS) based on the results of previous clinical trials involving predominantly women. This drug has been proven more effective than placebo at improving global and individual symptoms in patients with C-IBS, ${ }^{12,13}$ but has limited use in patients with IBS with diarrhea (D-IBS) because the augmented peristaltic reflex and accelerated colonic transit cause diarrhea, the most common adverse effect. ${ }^{11}$

However, most clinical trials about the efficacy of tegaserod on IBS were conducted in Western countries, ${ }^{12-15}$ and there are limited data from Asian countries. ${ }^{16,17}$ Furthermore, there has been little data available about the relationship between symptom improvement and change in QOL after treatment with tegaserod, ${ }^{18}$ and none in the Korean population.

The aim of this study was to evaluate the efficacy of treatment with tegaserod on symptoms of the IBS and to assess the impact on the QOL in female IBS patients with constipation in the
Korean population. We also wanted to evaluate the usefulness of IBS-QOL assessment as well as IBS symptoms in clinical studies about IBS treatment.

\section{Materials and Methods}

\section{Study design}

This study was a prospective, open labeled study and was conducted by 13 researchers in 9 university hospitals of Korea who were members of the IBS Club of the Korean Society of Neurogastroenterology and Motility. Each participating researcher enrolled consecutive adult female IBS patients with constipation as the predominant symptom, between November 2005 and February 2006. After checking the inclusion and exclusion criteria, the participating patients were asked to complete symptom questionnaire and IBS-QOL questionnaire as baseline data before treatment. Subsequently, $6 \mathrm{mg}$ of tegaserod twice daily was administered for 4 weeks, and then symptom questionnaire and IBS-QOL questionnaire were completed again.

\section{Patients}

Patient selection was based on a 3-month history of IBS symptoms, diagnosed using the Rome II criteria. ${ }^{19}$ Female patients, 18 years or older, were required to have abdominal pain or discomfort either relieved by a bowel movement, or associated with a change in the frequency of bowel movements or in the stool consistency. Patients were also required to have at least two of the following three constipation symptoms at least $25 \%$ of the time during the 3 months prior to study entry: less than three bowel movements per week, hard/lumpy stools or straining. In addition, patients with a mixed type of IBS could be enrolled if they showed a marked trend of constipation on the symptom severity questionnaire. Normal colonic anatomy had to be confirmed by colonoscopy or barium enema performed within 1 year. Patients were excluded from the study if they had a history of previous abdominal surgery (except appendectomy), state of pregnancy or lactation, severe systemic disease that could affect QOL, and any other significant digestive diseases (liver, pancreas, gall bladder, small, and large intestine). Patients who took medication specific for IBS (e.g., antidiarrheal, laxative, or antispasmodic drugs) within 6 months prior to the beginning of the study were also excluded. Medications affecting gastrointestinal motility and/or visceral perception, as well as antidepressants were not permitted 
during the treatment period. However, synthetic fiber or laxatives were permitted as a rescue medication.

\section{Questionnaires}

Bowel symptom and IBS-QOL questionnaire, which had been translated into Korean and validated in a previous linguistic and clinical study, ${ }^{20}$ were used in the present study. These questionnaires also included demographic factors such as age, marital status, level of education, annual income, and other combined diseases.

\section{1) Symptom questionnaire}

This questionnaire included the Rome II criteria and assessment of severity for eight symptom variables. The symptom variables were as following: abdominal pain or discomfort; hard or lumpy stools; loose or watery stools; straining during a bowel movement; having to rush to the toilet for a bowel movement; a feeling of incomplete bowel movement; passing mucus (white material) during a bowel movement; abdominal fullness, bloating, or swelling. All variables were divided into frequency and bothersomeness index assessed by a 7 point Likert scale $(0=$ never, $1=$ almost never, $2=$ seldom, $3=$ sometimes, $4=$ often, $5=$ almost always, $6=$ always). Total symptom score was defined as the sum of the symptom frequency and bothersomeness scores. The potential range of frequency or bothersomeness sum-score for all symptoms was 0 to 48 , and the range of total score was 0 to 96 . All questions were related to the previous 4 weeks of changes.

We also measured self-reported symptom severity using the question "How bad is the discomfort usually?" and discomfort in this question implied "pain and associated IBS symptoms". Responses were rated as mild (“can be ignored if I don't think about it"), moderate ("cannot be ignored, but does not affect my lifestyle"), or severe ("affects my lifestyle").

\section{2) IBS-QOL questionnaire}

Each patient also completed the IBS-QOL questionnaire initially developed by Patrick et al. ${ }^{21}$ The Korean version of this questionnaire (K-IBS-QOL) has been cross-culturally validated and used in a subsequent study by Park et al. ${ }^{20,22}$ It consists of 34 IBS-specific items with high internal consistency and reproducibility. Patients were asked to choose descriptive statements using a recall period of the previous 30 days. ${ }^{21} \mathrm{~A}$ five-point Likert scale was used to assess the degree of QOL by the statement describing the feelings of the respondent $(1=$ not at all, $2=$ slightly, 3 = moderately, $4=$ quite a bit, $5=$ extremely or a great deal). There were eight subscales: dysphoria interference with activities, body image, health worry, food avoidance, social reaction, sexual function, and relationships.

Subscales are scored through simple summative scaling. All items are negatively framed with the greatest response scale equaling the worst quality of life. When scored, all items are reversed so that as the IBS-QOL score increases, quality of life increases. All final raw scores are transformed into a 0 (poor quality of life) to 100 (maximum quality of life) scale using the following formula:

Scale score $=\{$ (the sum of the items - lowest possible score $) /$ possible raw score range $\} \times 100$

This transformation converted the lowest and highest possible scores into zero and 100, respectively. Scores between these values represented the percentage of the total possible score achieved. The IBS-QOL instrument and scoring programs have used this transformation to provide comparative data for interpretation. All items were sum-scored to calculate the overall score, which was also transformed into a 0-100 scale. If a patient responded with "not at all" for all 34 items, the overall score of IBS-QOL would be 100. If a patient responded with "slightly", a score of 4, for all items, the overall IBS-QOL score would be 80. Therefore, if a score was more than 80 , the subscale was not considered to be associated with bowel problems. Moderate to severe IBS had an approximate score of $60-65$ by the IBS-QOL. $^{23}$

\section{Statistical methods}

Symptom score and IBS-QOL score at baseline and at end of treatment were compared using paired $t$ test. The differences were considered statistically significant when a p-value $<0.05$ was obtained. The ANOVA and Pearson's correlation analysis were used to evaluate associations among patient's characteristics; symptom score change and QOL score change. The responder was defined when there was $\mathrm{a} \geq 2$ point reduction of sum score of each symptom variables from baseline according to the previous study. ${ }^{11,19}$ We used two endpoints for calculating the response rate. One was the change of abdominal pain or discomfort variable and the other was sum of changes of any significantly improved variables by tegaserod treatment (i.e., $\geq 2$ point reduction $\times$ number of improved variables). 
Table 1. Demographic Characteristics, Symptoms and Quality of Life of All Patients

\begin{tabular}{|c|c|c|c|c|c|c|c|c|c|c|}
\hline & Factor & $\mathrm{n}(\%)$ & $\begin{array}{c}\text { Total } \\
\text { symptom score } \\
(\text { mean } \pm \mathrm{SD})\end{array}$ & p-value & $\begin{array}{c}\text { Overall } \\
\text { QOL score } \\
(\text { mean } \pm \mathrm{SD})\end{array}$ & p-value & $\begin{array}{c}\text { Change of } \\
\text { total } \\
\text { symptom score } \\
\text { (mean } \pm \mathrm{SD} \text { ) }\end{array}$ & p-value & $\begin{array}{c}\text { Change of } \\
\text { overall } \\
\text { QOL score } \\
\text { (mean } \pm \mathrm{SD} \text { ) }\end{array}$ & p-value \\
\hline Total patients & & $81(100 \%)$ & $40.0 \pm 16.8$ & & $70.5 \pm 19.2$ & & $-9.1 \pm 17.9$ & & $4.6 \pm 17.1$ & \\
\hline \multirow[t]{5}{*}{ Age group } & $<30$ & $9(11.1 \%)$ & $49.2 \pm 11.5$ & NS & $63.8 \pm 21.5$ & NS & $-21.1 \pm 16.8$ & NS & $15.1 \pm 15.2$ & NS \\
\hline & $\geq 30,<40$ & $20(24.7 \%)$ & $42.2 \pm 19.3$ & & $73.1 \pm 18.1$ & & $-11.5 \pm 17.4$ & & $7.2 \pm 13.0$ & \\
\hline & $\geq 40,<50$ & $14(17.3 \%)$ & $45.0 \pm 18.9$ & & $66.6 \pm 20.3$ & & $-4.8 \pm 15.3$ & & $1.8 \pm 20.0$ & \\
\hline & $\geq 50,<60$ & $20(24.7 \%)$ & $33.0 \pm 15.7$ & & $71.9 \pm 22.6$ & & $-9.1 \pm 20.1$ & & $6.1 \pm 16.6$ & \\
\hline & $\geq 60$ & $18(22.2 \%)$ & $36.7 \pm 12.8$ & & $72.2 \pm 14.5$ & & $-3.9 \pm 16.8$ & & $-3.2 \pm 18.3$ & \\
\hline \multirow[t]{3}{*}{ Duration } & $<2$ years & $25(30.9 \%)$ & $38.1 \pm 18.4$ & NS & $74.9 \pm 18.4$ & NS & $-7.1 \pm 20.2$ & NS & $3.4 \pm 19.4$ & NS \\
\hline & $2-4$ years & $10(12.3 \%)$ & $36.6 \pm 17.9$ & & $61.2 \pm 23.7$ & & $-9.3 \pm 24.2$ & & $10.9 \pm 19.8$ & \\
\hline & $>4$ years & $46(56.8 \%)$ & $41.7 \pm 15.8$ & & $70.1 \pm 18.1$ & & $-10.2 \pm 15.3$ & & $3.9 \pm 15.2$ & \\
\hline \multirow{3}{*}{$\begin{array}{l}\text { Number of } \\
\text { hospital visit }\end{array}$} & $<2 / 6$ months & $46(56.8 \%)$ & $36.9 \pm 17.3$ & $<0.05$ & $76.1 \pm 17.9$ & $9<0.01$ & $-9.5 \pm 18.5$ & NS & $3.9 \pm 18.3$ & NS \\
\hline & $2-4 / 6$ months & $20(24.7 \%)$ & $38.5 \pm 13.6$ & & $66.0 \pm 17.2$ & & $-6.8 \pm 15.5$ & & $2.7 \pm 13.7$ & \\
\hline & $>4 / 6$ months & $15(18.5 \%)$ & $51.3 \pm 15.4$ & & $59.4 \pm 20.1$ & & $-11.1 \pm 20.1$ & & $9.0 \pm 18.0$ & \\
\hline \multirow{3}{*}{$\begin{array}{l}\text { Self-reported } \\
\text { symptom } \\
\text { severity }\end{array}$} & Mild & $4(4.9 \%)$ & $34.5 \pm 32.0$ & NS & $64.7 \pm 24.9$ & $<0.01$ & $0.3 \pm 21.7$ & NS & $-1.3 \pm 17.2$ & NS \\
\hline & Moderate & $33(40.7 \%)$ & $36.2 \pm 16.6$ & & $78.3 \pm 17.1$ & & $-10.5 \pm 15.7$ & & $4.1 \pm 14.4$ & \\
\hline & Severe & $44(54.3 \%)$ & $43.4 \pm 15.0$ & & $65.1 \pm 18.6$ & & $-8.9 \pm 19.3$ & & $5.5 \pm 19.2$ & \\
\hline \multirow{3}{*}{$\begin{array}{l}\text { Level of } \\
\text { education }\end{array}$} & Less than high school & $21(25.9 \%)$ & $37.4 \pm 18.5$ & NS & $69.1 \pm 16.4$ & NS & $-8.9 \pm 18.8$ & NS & $2.1 \pm 17.6$ & NS \\
\hline & High school & $29(35.8 \%)$ & $38.7 \pm 18.8$ & & $72.0 \pm 21.5$ & & $-4.2 \pm 19.5$ & & $1.5 \pm 17.6$ & \\
\hline & More than high school & $31(38.3 \%)$ & $43.0 \pm 13.4$ & & $69.9 \pm 19.1$ & & $-13.8 \pm 14.9$ & & $9.1 \pm 15.9$ & \\
\hline \multirow{3}{*}{$\begin{array}{l}\text { Marital } \\
\text { status }\end{array}$} & Married & $55(67.9 \%)$ & $38.8 \pm 16.7$ & $<0.05$ & $72.0 \pm 20.1$ & NS & $-7.4 \pm 17.8$ & NS & $2.6 \pm 18.3$ & NS \\
\hline & Single & $7(8.6 \%)$ & $30.1 \pm 18.7$ & & $63.2 \pm 14.4$ & & $-4.7 \pm 22.8$ & & $9.0 \pm 10.6$ & \\
\hline & Divorced/Bereavement & $19(23.5 \%)$ & $47.1 \pm 14.3$ & & $68.9 \pm 18.1$ & & $-15.8 \pm 15.6$ & & $8.6 \pm 15.2$ & \\
\hline \multirow{3}{*}{$\begin{array}{l}\text { Annual } \\
\text { income }^{a}\end{array}$} & $<\$ 20,000$ & $17(20.9 \%)$ & $41.6 \pm 18.1$ & NS & $70.9 \pm 17.0$ & NS & $-8.6 \pm 14.1$ & NS & $-2.9 \pm 16.6$ & NS \\
\hline & $\$ 20,000-\$ 40,000$ & $13(16.0 \%)$ & $40.4 \pm 15.9$ & & $69.7 \pm 19.1$ & & $-6.0 \pm 14.6$ & & $3.7 \pm 8.7$ & \\
\hline & $>\$ 40,000$ & $15(18.5 \%)$ & $42.9 \pm 20.1$ & & $72.8 \pm 19.6$ & & $-17.6 \pm 23.0$ & & $10.4 \pm 26.1$ & \\
\hline
\end{tabular}

${ }^{a}$ Thirty six patients (44.4\%) did not respond to this question.

$\mathrm{SD}$, standard deviation; QOL, quality of life; NS, not significant.

\section{Results}

\section{Baseline characteristics of patient}

A total of 81 female patients from 9 centers were enrolled in this study. All patients were women aged 18-73 years. Table 1 showed the demographic features for all 81 female participants and both their symptom score and QOL score. The mean age of total participants was 46.2 years, $56.8 \%$ had the disease for over 4 years and $67.9 \%$ were married. Age, duration of disease, level of education, and economic status did not affect the baseline symptom score or QOL score, but total symptom score differed according to marital status. Number of hospital visits showed good correlation with both total symptom score $(<0.05)$ and QOL score $(\mathrm{p}<0.01)($ Table 1$)$.
Table 2. Summary of the Baseline Symptoms among 81 Patients

\begin{tabular}{lcc}
\hline \multicolumn{1}{c}{ Symptoms } & $\begin{array}{c}\text { Number (\%) } \\
\text { of affected } \\
\text { patients }\end{array}$ & $\begin{array}{c}\text { Mean } \\
\text { score of all } \\
\text { patients }\end{array}$ \\
\hline Fewer than three bowel movements a week & $65(80.2)$ & \\
More than three bowel movements a week & $4(4.9)$ & \\
Abdominal pain or discomfort & $81(100)$ & 6.38 \\
Hard or lumpy stool & $63(77.8)$ & 5.54 \\
Loose or watery stool & $20(24.7)$ & 3.54 \\
Straining during bowel movement & $63(77.8)$ & 6.35 \\
Urgency & $14(17.3)$ & 3.33 \\
Feeling of incomplete bowel movement & $70(86.4)$ & 6.79 \\
Passing mucus & $18(22.2)$ & 1.47 \\
Abdominal fullness, bloating, or swelling & $65(80.3)$ & 6.58 \\
\hline
\end{tabular}

\section{Baseline symptom score and IBS-QOL score}

Frequently reported symptoms of subjects on the baseline 
symptom questionnaire were incomplete bowel movement, abdominal bloating, fewer than three bowel movements a week, hard or lumpy stool, and straining during bowel movement in order of prevalence (Table 2). Self-reported severity of their bowel symptoms classified as mild, moderate and severe was $5 \%$, $40.7 \%$, and $54.3 \%$, respectively. Self-reported symptom severity

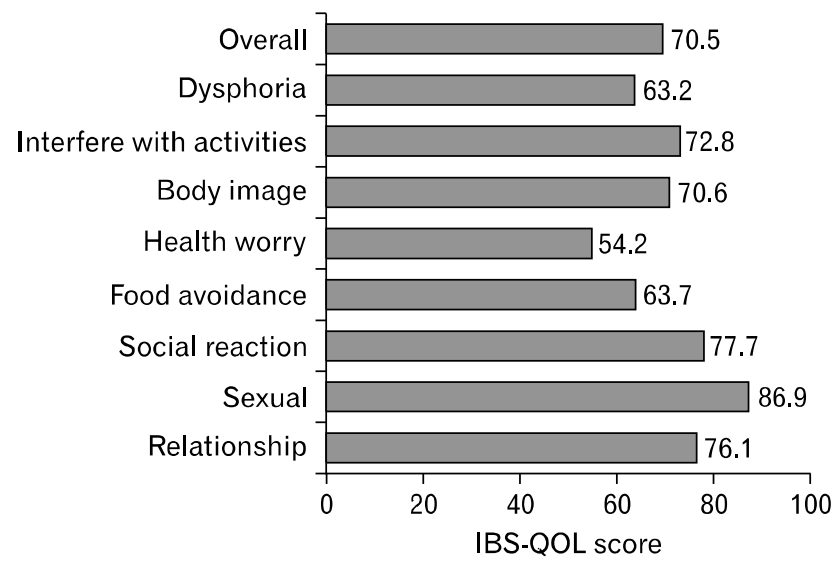

Figure 1. Baseline IBS-QOL score of all patients $(\mathrm{n}=81)$. The dysphoira, health worry, and food avoidance subscales showed the greatest impairments among 8 subscales. The sexual function subscale was not considered to be associated with bowel problems. significantly correlated with baseline QOL score $(r=-0.23, p$ $<0.05)$ but not with baseline symptom score. Fig. 1 showed the baseline IBS-QOL score of patients. Of the 8 subscales, the greatest impairments (i.e., scores below 65) were seen with dysphoira, health worry, and food avoidance subscales. The score of sexual function subscale was 86.85, therefore it was not considered to be associated with bowel problems. The dysphoria, interference with activities, body image, health worry, social reaction subscales $(r=-0.47,-0.46,-0.48,-0.46$, and -0.51 respectively, $\mathrm{p}<0.001)$ and overall IBS-QOL score $(\mathrm{r}=$ $-0.52, \mathrm{p}<0.001)$ showed a stronger correlation with symptom score than the food avoidance and relationships subscales $(r=$ -0.38 and $-0.39, \mathrm{p}<0.001)$.

\section{Symptom score outcome}

Tegaserod significantly improved overall symptoms score, symptom frequency and symptom bothersomeness after 4 weeks of therapy (Fig. 2A). The response rate using the abdominal pain or discomfort variable was $49.4 \%$ (40/81) and their mean decreased score was 4.43. In analysis of individual variables, tegaserod significantly improved abdominal pain or discomfort, hard or lumpy stool, straining during bowel movement, feeling of incomplete bowel movement, and abdominal fullness or bloating $(\mathrm{p}<0.01)$. But tegaserod did not influence loose or watery

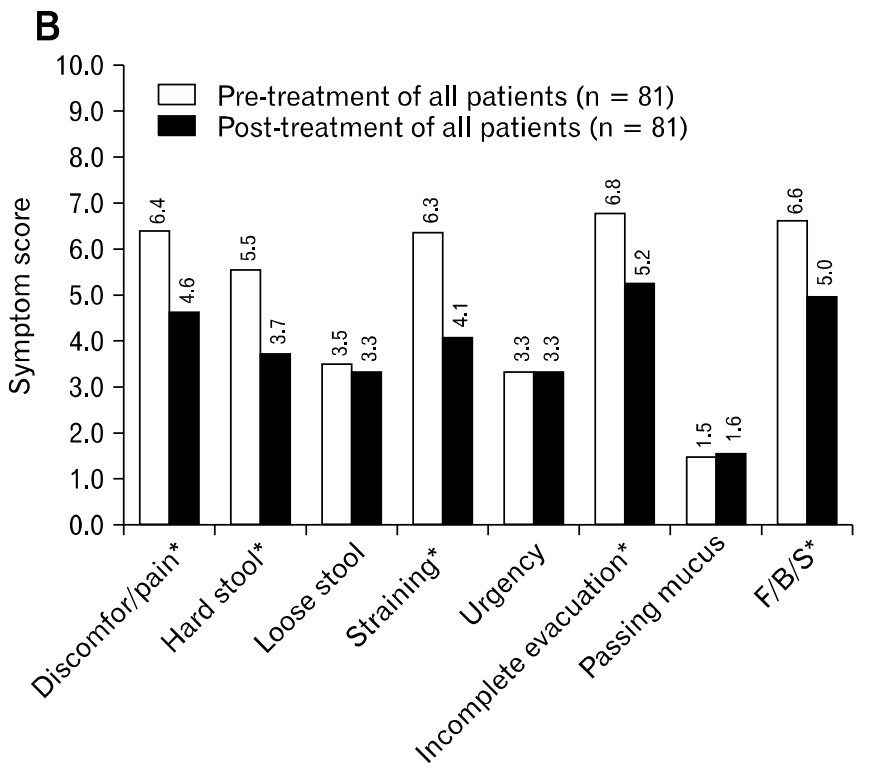

Figure 2. The change of irritable bowel syndrome symptoms after treatment of tegaserod. (A) The overall symptoms scores, symptom frequency and symptom bothersomeness were improved after 4 weeks of therapy. (B) Tegaserod improved abdominal pain or discomfort, hard or lumpy stool, straining during bowel movement, feeling of incomplete bowel movement, and abdominal fullness or bloating among eight symptom variables. * $\mathrm{p}<0.01$. F, fullness; B, bloating; $\mathrm{S}$, swelling. 
stools, urgency, or passing mucus (Fig. 2B). The response rate that was calculated by a $\geq 10$ point reduction in sum-score of five significantly improved variables from baseline was $43.2 \%$ $(35 / 81)$ and their mean decreased sum score was 22.54. We used this value as the reference for definition of responder and analysis of QOL in this study. The baseline scores of these five symptom variables were significantly higher in responders than nonresponders (Fig. 3). A small portion of patients reported that their symptoms were aggravated after tegaserod therapy, even with the above five significantly improved variables, and interestingly $24.7 \%$ of patients reported that the feeling of incomplete bowel movement was aggravated after medication (Table 3). Unlike the basal symptom score, there was no significant correlation between demographic factors and the degree of improvement of symptom scores (Table 1), and there was no statistical difference in demographic factors between responders and nonresponders.

\section{Quality of life outcome}

Tegaserod significantly improved the overall IBS-QOL score after 4 weeks $(\mathrm{p}<0.05)$. After treatment, the overall IBS-QOL score increased in $67.9 \%$ of patients compared to the baseline. In analysis of individual subscales between pre- and post-treatment for all patients, tegaserod significantly improved dysphoria, body image, health worry, and food avoidance subscales. But tegaserod did not influence interference with activities, social reaction, sexual function, and relationships subscales (Fig. 4A). Unlike the basal QOL score, there was no significant correlation between demographic factors and the degree of improvement of QOL score (Table 1). There was also no significant difference in baseline QOL score between responders and nonresponders.

\section{Relationship between improvement of symptoms and QOL change}

We analyzed individual subscales of QOL at pre- and posttreatment period according to responders and nonresponders. All QOL subscales except the sexual function subscale were significantly improved by tegaserod treatment in the responders with the greatest changes in dysphoria and social reaction subscale (Fig. 4B). However, no subscale was improved in

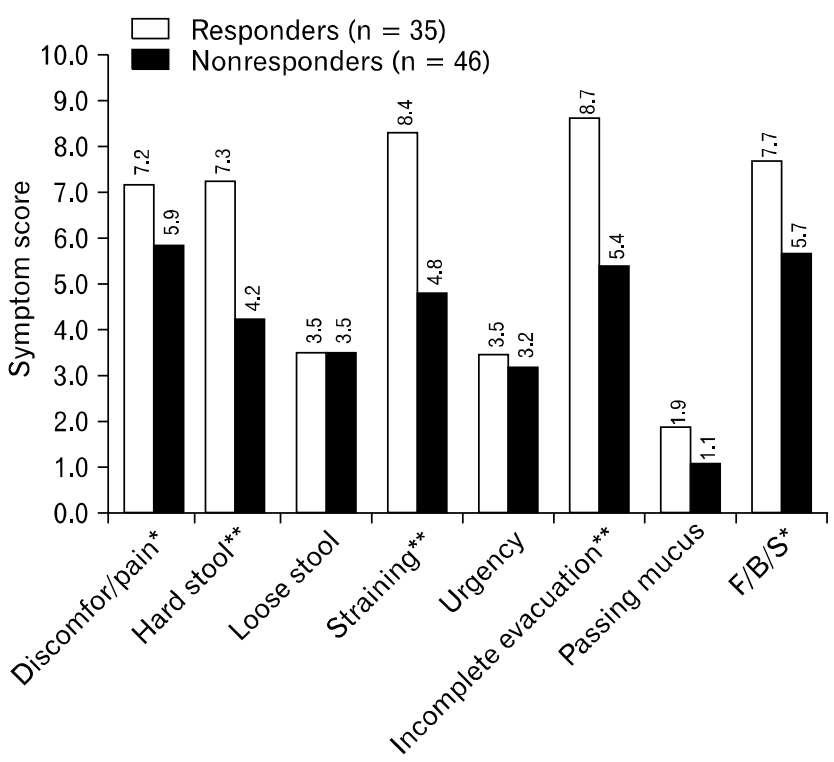

Figure 3. The baseline symptom score according to responders and nonresponders. When patients were divided into responders and nonresponders, the baseline scores of five improved symptom variables were significantly higher in responders than nonresponders, but there was no difference of baseline QOL score between responders and nonresponders. ${ }^{*} \mathrm{p}<$ $0.05,{ }^{*} \mathrm{p}<0.01$. F, fullness; B, bloating; S, swelling.

Table 3. Response Rate according to Symptom Score Variables

\begin{tabular}{|c|c|c|c|c|}
\hline \multirow[b]{2}{*}{ Variables } & \multicolumn{2}{|c|}{$\geq 2$ point decrement from baseline } & \multicolumn{2}{|c|}{$\geq 2$ point increment from baseline } \\
\hline & $\begin{array}{l}\text { Number of } \\
\text { patient }(\%)\end{array}$ & $\begin{array}{c}\text { Mean score change } \\
\text { of responders }\end{array}$ & $\begin{array}{l}\text { Number of } \\
\text { patient }(\%)\end{array}$ & $\begin{array}{c}\text { Mean score change } \\
\text { of responders }\end{array}$ \\
\hline Abdominal pain or discomfort & $40(49.4)$ & -4.43 & $10(12.3)$ & +4.40 \\
\hline Hard or lumpy stool & $39(48.1)$ & -5.05 & $11(13.6)$ & +4.82 \\
\hline Loose or watery stools & $28(34.6)$ & -4.04 & $18(22.2)$ & +5.00 \\
\hline Straining during bowel movement & $43(53.1)$ & -5.40 & $12(14.8)$ & +4.00 \\
\hline Urgency & $30(37.0)$ & -3.47 & $21(25.9)$ & +4.71 \\
\hline Feeling of incomplete bowel movement & $40(49.4)$ & -4.60 & $20(24.7)$ & +3.35 \\
\hline Passing mucus & $13(16.1)$ & -4.15 & $17(21.0)$ & +3.53 \\
\hline Abdominal fullness, bloating, or swelling & $42(51.9)$ & -4.36 & $15(18.5)$ & +4.00 \\
\hline
\end{tabular}


A

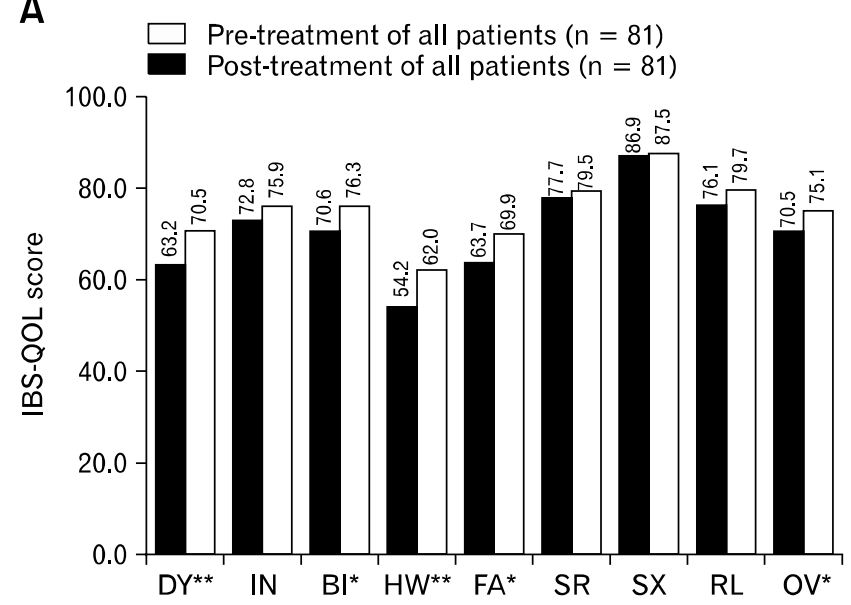

C

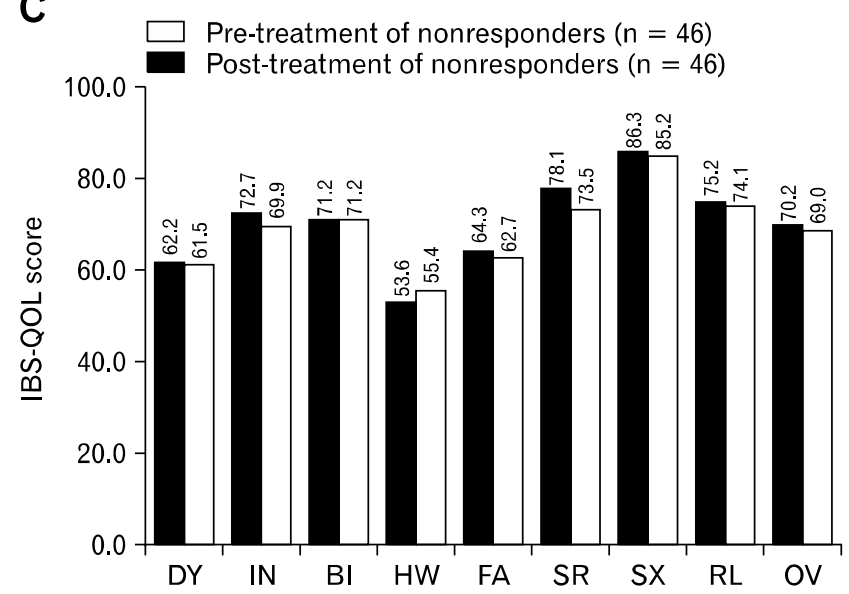

nonresponders and the QOL scores were rather decreased except the health worry subscale, but this decrease was not significant (Fig. 4C).

To evaluate the relationship between degree of symptomatic improvement and QOL improvement, we divided patients into three response categories using the sum-scores of above five symptom variables (improving: decrease $\geq 10$ point; no change: decrease or increase $<10$ point; worsening: increase $\geq 10$ point from pre- to post-treatment). Patients with more symptomatic improvement showed a greater increase in IBS-QOL score (Fig. $5 A)$. The overall IBS-QOL score change of 12.26 from pre- to post-treatment in an improving group is significantly greater than no change ( $\mathrm{p}<0.01)$ or worsening group $(\mathrm{p}<0.01)$, but there was no significant difference between no change and worsening group $(p>0.05)$. There was a strong correlation between the improvement of symptom score and improvement of individual IBS-QOL subscale score or overall IBS-QOL score (Fig. 5B, r
B

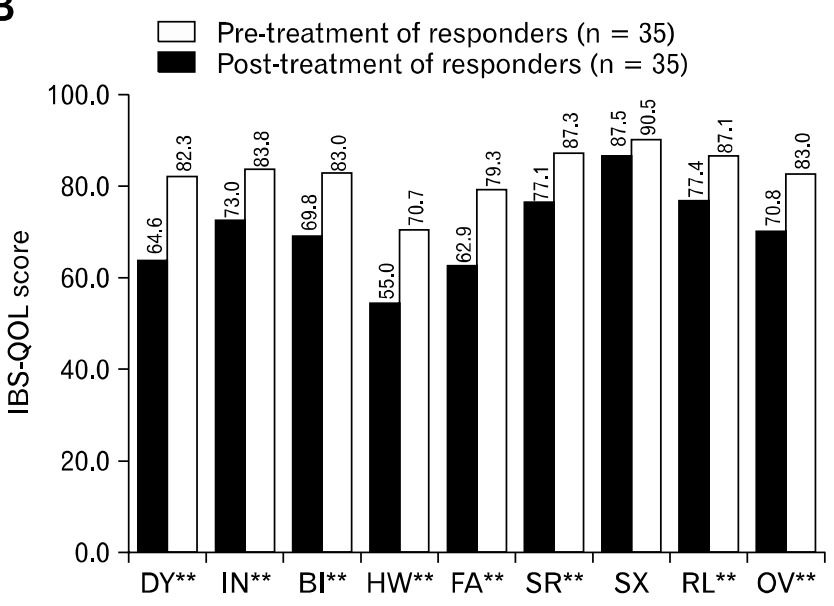

Figure 4. The change of IBS-QOL score after treatment of tegaserod. (A) Dysphoria, body image, health worry, and food avoidance subscale among eight subscales were improved after 4 weeks of therapy. When patients were divided into responders and nonresponders, there was a significant improvement of all subscale except sexual function subscale in responders (B), but no subscales were improved in nonresponders (C). ${ }^{*} \mathrm{p}<0.05,{ }^{*} \mathrm{p}<0.01$. DY, dysphoria; IN, interfere with activity; $\mathrm{BI}$, body image; $\mathrm{HW}$, health worry; FA, food avoidance; SR, social reaction; SX, sexual; $\mathrm{RL}$, relationship; OV, overall.

$=-0.60, \mathrm{p}<0.001)$.

\section{Discussion}

This nationwide, multicenter, prospective study is the first to report the therapeutic impact of tegaserod on QOL in Korean female patients with IBS. IBS is widely distributed in Western and Eastern countries and tegaserod has been used for IBS treatment worldwide including in Korea. Tegaserod was approved for the treatment of female patients with IBS-C in July 2002. ${ }^{11,18}$ Although tegaserod was removed from the worldwide market in March 2007 because of the possible cardiovascular adverse effects, it is still worthwhile to evaluate their efficacy in patients with IBS for further development of serotonergic drugs for the management of IBS. The present study demonstrated that tegaserod improved abdominal pain or discomfort, hard or lumpy stool, and bloating in spite of its short treatment duration. This 
A

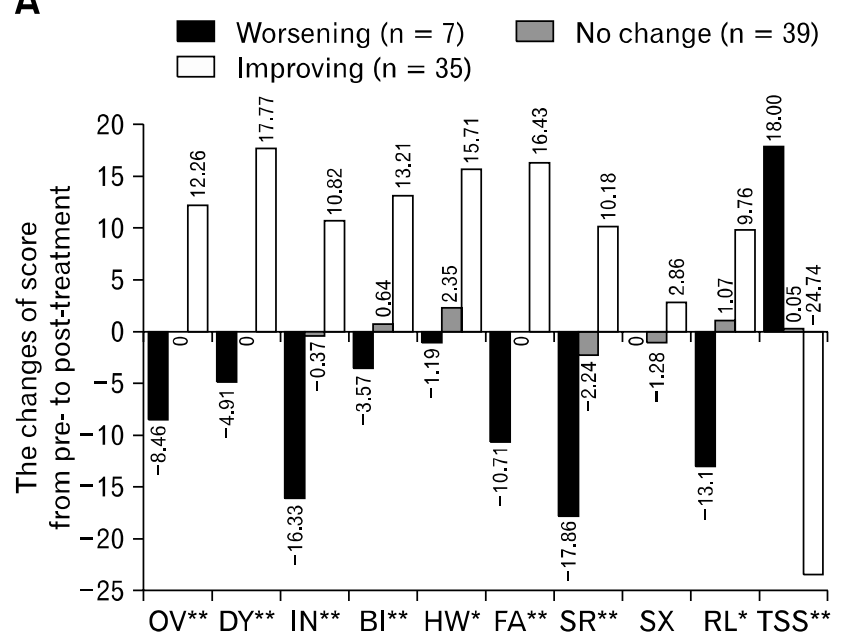

B

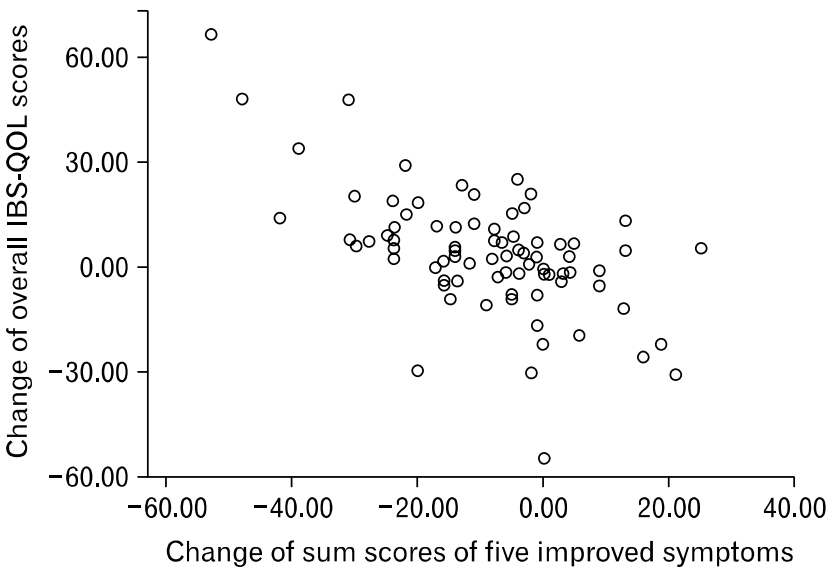

Figure 5. Changes in IBS-QOL in subgroups by clinical responses and correlation between symptom change and quality of life change. (A) There was a strong negative correlation between total symptom score change and quality of life score change. The more symptom score decreased, the more quality of life score improved. If symptom was aggravated after treatment, quality of life was aggravated with greater score reduction in interference with activities, social reaction, and relationship subscales than other subscales. (B) There was a strong negative correlation between the improvement of five symptom score (sum of abdominal pain or discomfort, hard or lumpy stool, straining during bowel movement, feeling of incomplete bowel movement, and abdominal fullness or bloating) and overall IBS-QOL score $(\mathrm{r}=-0.60, \mathrm{p}$ $<0.001)$. Correlations with symptom score of other subscales were also significant ( $\mathrm{R}=\mathrm{DY}-0.57$; IN $-0.54 ; \mathrm{BI}-0.52 ; \mathrm{HW}-0.43$; FA -0.44; SR -0.55; SX nonspecific; RL -0.46, p < 0.001). ${ }^{*} p<0.05,{ }^{*} \mathrm{p}<0.01$. DY, dysphoria; IN, interfere with activity; BI, body image; HW, health worry; FA, food avoidance; SR, social reaction; SX, sexual; RL, relationship; OV, overall; TSS, total symptom score.

result is consistent with that of the previous studies. ${ }^{12,13,15,18}$ Tegaserod not only significantly accelerates gastric emptying and transit time of small bowel and colon but also reduces the sensitivity to rectal distension. Our study also showed that straining and feeling of incomplete bowel movement were improved and this result supports the theory that tegaserod affects visceral sensation as well as gastrointestinal motility. ${ }^{24,25}$ However, the Asian-Pacific population study did not demonstrate a significant differences in these two symptoms ${ }^{17}$ and this inconsistency of results may be due to differences in study design and population.

The response rate of clinical studies depends on race, region and treatment duration. IBS patients experience multiple symptoms and there is no definite biomarker, therefore it is very important to choose the proper primary end-point in the clinical trial that evaluates the efficacy of therapeutic drugs on IBS. The response rate in studies using the Subject's Global Assessment (SGA, question like "Did you have satisfactory relief of your overall IBS symptoms during the treatment period?") was $56 \%$ for 4 weeks in Asian population, ${ }^{17} 40.5 \%$ for 4 weeks in US population, ${ }^{13}$ and $30.5 \%$ for 4 weeks ${ }^{14}$ and $46.3 \%$ for 12 weeks $^{12}$ in European population. In the most recent, largest $(n=2,660)$, multinational study of Western countries, the response rate was
$41.8 \%$ for 4 weeks. ${ }^{16}$ Although some guidelines recommended to use subjective symptomatic relief as a primary end-point and it has been commonly used in most clinical trials, these parameters could not capture the entire effect on individual symptoms and may have underestimated the effectiveness of the drug. ${ }^{26,27}$ The IBS patients with mild baseline symptoms were more likely to report satisfactory relief than those with moderate or severe symptoms. Conversely, the IBS patients with severe baseline symptoms showed the greatest reduction in symptom score but were least likely to report satisfactory relief. ${ }^{28}$ For this reason, we assessed eight individual symptom scores before and after treatment as the primary end-point instead of SGA in this study. Novic et al. ${ }^{13}$ reported that tegaserod was associated with a statistically significant higher improvement than placebo and mean score differences (end-point minus baseline of bothersome score) of tegaserod/placebo in abdominal pain and bowel habit were $-1.01 /-0.80$ and $-1.30 /-0.95$, respectively. Based on this result and other clinical study, ${ }^{15}$ we defined the responder in this study as a $\geq 2$ point reduction from baseline sum score (frequency plus bothersomeness) and the response rate of abdominal pain/discomfort was $49.4 \%$. This result is comparable with the response rate (47.8\%) for abdominal discomfort/pain in the recent largest, multinational Western study which used 
similar definition. ${ }^{15}$

IBS-specific quality of life has rarely been used as a primary end-point in the assessment of the effect of tegaserod on IBS, but IBS patients suffer from impaired health-related QOL as well as their IBS-related bowel symptoms. ${ }^{7-9}$ Therefore, it is useful to evaluate the effect on QOL of patients with IBS by certain medication in clinical trials. However most clinical studies usually assessed symptomatic improvement or used only a summary score even if QOL was assessed. The pattern of bowel symptoms related to IBS seems to be similar across the country, ${ }^{29}$ but quality of life perceived by IBS patients varied depending on different cultural environments and countries rather than racial differences. ${ }^{30,31}$

In the current study, the subscales with low scores (60-65) that can be considered as moderate to severe IBS were dysphoria, health worry, and food avoidance subscale and the score of health worry subscale was lowest. This result suggests that IBS patients suffer more from anxiety about their disease than impairment of social activity or relationship by bowel symptom. This poor QOL is an important factor that causes patients to consider their disease severe and self-reported severity only significantly correlated with QOL score, but not symptom score. For this reason, the assessment of IBS-QOL should be included as part of the therapeutic outcome in clinical trials that assess the efficacy of certain drugs on IBS patients.

The score of sexual function subscale was over 80 points and was not affected by tegaserod therapy in the present study, but there was a possibility that subjects did not report their actual sexual life. Koreans, especially females who make up the current study population, are reluctant to express sexual problems and this tendency was already observed in the previous study. ${ }^{20}$

There was no difference of baseline QOL between responders and nonresponders, but QOL was significantly improved in responder group. Interestingly, if symptom was aggravated after treatment, there was a tendency of decrease in QOL with greater score reduction in the subscales of interference with activities, social reaction, and relationship than other subscales. This result suggests that as bowel symptoms become severe, the QOL about social activity is more impaired than the QOL about disease-related worry.

Based on these results, it is suggested that we should try the bowel-directed treatment first, for the IBS-related anxiety and poor QOL and then if there is no improvement by this general management, additional treatment modality, such as antidepressant or psychiatric treatment, should be considered.
We found a strong inverse correlation between baseline symptom score and QOL score and good categorization of QOL score change according to symptomatic response group to tegaserod treatment. In aspect of usefulness of IBS-QOL in clinical studies for IBS treatment, therefore, it seems to be used as a primary end-point and has a role in support of subjective symptomatic end-point to evaluate and monitor efficacy of certain drug. Additionally IBS-QOL can characterize the patients according to their responsiveness and acts as an indicator for the clinical course of patients with IBS under treatment.

This study has limitations since it was not a placebo controlled study and there has been no consensus about the definition of responder in the scoring system. We used p-value $<0.05$ or $\geq 2$ point reduction from baseline score as response indicator according to previous study, but $\mathrm{p}$-value or certain reduction of score do not imply whether a particular finding has clinical implications.

Until now, there have been few available data from well-designed studies about the impact of tegaserod on QOL. Therefore, it is necessary to study about the clinically meaningful threshold of scoring system and more clinical trials using IBS-QOL questionnaire for specific culture, nation, and race are needed.

In conclusion, current results suggest that tegaserod $6 \mathrm{mg}$ twice daily is effective for improvement of the QOL as well as the bowel symptoms in Korean female patients with IBS whose primary symptom is constipation. In addition, the IBS-QOL can be used as a reliable end-point in IBS clinical study and provide with additional useful information in clinical practice.

\section{Acknowledgments}

We thank Donald L. Patrick for kindly consenting to the use of the IBS-QOL in Korea.

\section{References}

1. Drossman DA. Introduction. The Rome foundation and Rome III. Neurogastroenterol Motil 2007;19:783-786.

2. Camilleri M, Choi MG. Review article: irritable bowel syndrome. Aliment Pharmacol Ther 1997;11:3-15.

3. Jones R, Lydeard S. Irritable bowel syndrome in the general population. BMJ 1992;304:87-90.

4. Boyce PM, Talley NJ, Burke C, Koloski NA. Epidemiology of the functional gastrointestinal disorders diagnosed according to Rome II criteria: an Australian population-based study. Intern Med J 2006;36:28-36 
5. Drossman DA, Camilleri M, Mayer EA, Whitehead WE. AGA technical review on irritable bowel syndrome. Gastroenterology 2002;123:2108-2131.

6. Han SH, Lee OY, Bae SC, et al. Prevalence of irritable bowel syndrome in Korea: population-based survey using the Rome II criteria. J Gastroenterol Hepatol 2006;21:1687-1692.

7. Gralnek IM, Hays RD, Kilbourne A, Naliboff B, Mayer EA. The impact of irritable bowel syndrome on health-related quality of life. Gastroenterology 2000;119:654-660.

8. El-Serag HB, Olden K, Bjorkman D. Health-related quality of life among persons with irritable bowel syndrome: a systematic review. Aliment Pharmacol Ther 2002;16:1171-1185.

9. Dean BB, Aguilar D, Barghout V, et al. Impairment in work productivity and health-related quality of life in patients with IBS. Am J Manag Care 2005;11(suppl 1):17-26.

10. Gershon M. Review article: serotonin receptors and transportersroles in normal and abnormal gastrointestinal motility. Aliment Pharmacol Ther 2004;20(suppl 7):3-14.

11. Lacy BE, Yu S. Tegaserod: a new 5-HT4 agonist. J Clin Gastroenterol 2002;34:27-33.

12. Müller-Lissner SA, Fumagalli I, Bardhan KD, et al. Tegaserod, a $5-\mathrm{HT}_{4}$ receptor partial agonist, relieves symptoms in irritable bowel syndrome patients with abdominal pain, bloating and constipation. Aliment Pharmacol Ther 2001;15:1655-1666.

13. Novick J, Miner P, Krause R, et al. A randomized, double-blind, placebo-controlled trial of tegaserod in female patients suffering from irritable bowel syndrome with constipation. Aliment Pharmacol Ther 2002;16:1877-1888.

14. Nyhlin H, Bang C, Elsborg L, et al. A double-blind, placebo-controlled, randomized study to evaluate the efficacy, safety, and tolerability of tegaserod in patients with irritable bowel syndrome. Scand J Gastroenterol 2004;39:119-126.

15. Tack J, Müller-Lissner S, Bytzer P, et al. A randomised controlled trial assessing the efficacy and safety of repeated tegaserod therapy in women with irritable bowel syndrome with constipation. Gut 2005; 54:1707-1713.

16. Tegaserod Clinical Research Group. A randomized, double-blind, placebo-controlled, multicenter study to assess the efficacy and safety of tegaserod in Chinese patients with constipation-predominant irritable bowel syndrome. Zhonghua Nei Ke Za Zhi 2003;42:88-90.

17. Kellow J, Lee OY, Chang FY, et al. An Asia-Pacific, double blind, placebo controlled, randomised study to evaluate the efficacy, safety, and tolerability of tegaserod in patients with irritable bowel syndrome. Gut 2003;52:671-676.

18. Evans BW, Clark WK, Moore DJ, Whorwell PJ. Tegaserod for the treatment of irritable bowel syndrome and chronic constipation.
Cochrane Database Syst Rev 2007;(4):CD003960.

19. Thompson WG, Longstreth GF, Drossman DA, Heaton KW, Irvine EJ, Müller-Lissner SA. Functional bowel disorders and functional abdominal pain. Gut 1999;45(suppl 2):1143-1147

20. Park JM, Choi MG, Oh JH, et al. Cross-cultural validation of irritable bowel syndrome quality of life in Korea. Dig Dis Sci 2006;51: 1478-1484.

21. Patrick DL, Drossman DA, Frederick IO, DiCesare J, Puder KL. Quality of life in persons with irritable bowel syndrome: development and validation of a new measure. Dig Dis Sci 1998;43:400-411.

22. Park JM, Choi MG, Kim YS, et al. Quality of life of patients with irritable bowel syndrome in Korea. Qual Life Res 2009;18:435-446.

23. Drossman D, Morris CB, Hu Y, et al. Characterization of health related quality of life (HRQOL) for patients with functional bowel disorder (FBD) and its response to treatment. Am J Gastroenterol 2007;102:1442-1453.

24. Degen L, Petrig C, Studer D, Schroller S, Beglinger C. Effect of tegaserod on gut transit in male and female subjects. Neurogastroenterol Motil 2005;17:821-826.

25. Coffin B, Farmachidi JP, Rueegg P, Bastie A, Bouhassira D. Tegaserod, a $5-\mathrm{HT}_{4}$ receptor partial agonist, decreases sensitivity to rectal distension in healthy subjects. Aliment Pharmacol Ther 2003;17: 577-585.

26. Müller-Lissner S, Koch G, Talley NJ, et al. Subject's global assessment of relief: an appropriate method to assess the impact of treatment on irritable bowel syndrome-related symptoms in clinical trials. J Clin Epidemiol 2003;56:310-316.

27. Corazziari E, Bytzer P, Delvaux M, et al. Clinical trial guidelines for pharmacological treatment of irritable bowel syndrome. Aliment Pharmacol Ther 2003;18:569-580.

28. Whitehead WE, Palsson OS, Levy RL, Feld AD, VonKorff M, Turner M. Reports of "satisfactory relief" by IBS patients receiving usual medical care are confounded by baseline symptom severity and do not accurately reflect symptom improvement. Am J Gastroenterol 2006;101:1057-1065.

29. Talley NJ, Holtmann G, Agreus L, Jones M. Gastrointestinal symptoms and subjects cluster into distinct upper and lower groupings in the community: a four nations study. Am J Gastroenterol 2000;95: 1439-1447.

30. Faresjo A, Anastasiou F, Lionis C, Johansson S, Wallander MA, Faresjo T. Health-related quality of life of irritable bowel syndrome patients in different cultural settings. Health Qual Life Outcomes 2006;4:21.

31. Gralnek IM, Hays RD, Kilbourne AM, Chang L, Mayer EA. Racial differences in the impact of irritable bowel syndrome on health-related quality of life. J Clin Gastroenterol 2004;38:782-789. 